\title{
A Atividade de Estudo segundo V. V. Repkin: uma abordagem crítica na perspectiva da Teoria da Subjetividade ${ }^{1}$
}

\author{
Roberto Valdés Puentes ${ }^{2}$ \\ Cecília Garcia Coelho Cardoso ${ }^{3}$ \\ Paula Alves Prudente Amorim 4
}

\section{RESUMO}

$\mathrm{O}$ artigo aborda do ponto de vista teórico duas questões fundamentais. Em primeiro lugar, alguns dos pressupostos psicológicos e didáticos da teoria da Atividade de Estudo e sua importância na organização dos processos na perspectiva da Didática Desenvolvimental e do sistema Elkonin-Davidov-Repkin, a partir das contribuições de V. V. Repkin. Em segundo, uma análise crítica da visão de V. V. Repkin dessa concepção a luz da Teoria da Subjetividade. Concluiu-se que a obra de V. V. Repkin, vinculada a Atividade de Estudo, merece ser reconhecida como um aporte importante no campo da psicologia e da didática marxistas da época vigência nos momentos atuais. A mesma incorreu em erros filosóficos e conceituais que poderiam ser considerados expressão de uma época e de um momento específico do desenvolvimento da ciência psicológica e didática no período soviético. Com base na Teoria da Subjetividade, as principais críticas a obra de V. V. Repkin sobre Atividade de Estudo são: o caráter pelo menos aparentemente determinista da atividade objetiva (externa) em relação a subjetiva (interna); a compreensão da Atividade de Estudo enquanto processo de interiorização dos conhecimentos, negando com isso o caráter gerador e criativo do sujeito que aprende; o predomínio do caráter cognitivista dos processos didáticos, com o que se

\footnotetext{
${ }^{1} \mathrm{O}$ artigo faz parte de uma pesquisa que contou com o apoio da CAPES, CNPq e Fapemig.

2 Doutor em Educação. Docente do Curso de Pedagogia e do Programa de Pós-Graduação em Educação da Universidade Federal de Uberlândia, PPGED/FACED/UFU. Contato: robertovaldespuentes@ gmail.com

${ }^{3}$ Graduada em Pedagogia. Estudante do PPGED da Universidade Federal de Uberlândia no nível de mestrado. Email: ceciliagcc@yahoo.com.br

${ }^{4}$ Graduada em Pedagogia. Estudante do PPGED da Universidade Federal de Uberlândia no nível de mestrado. Email: paulaped.alves@yahoo.com.br
} 
nega a unidade do simbólico e do emocional na constituição da subjetividade; a negação do aluno como sujeito de sua própria atividade.

PALAVRAS-CHAVE: Atividade de Estudo; V. V. Repkin; Teoria da Subjetividade.

Study activity according to V.V.Repkin: a critical approach under the perspective of the Subjectivity theory

\begin{abstract}
The article approaches from the theoretical point of view, two fundamental questions. First place, some of the psychological and didactic presuppositions of the Activity theory and its importance in the organization of processes under the Developmental perspective and the Elkonin-Davidov system, from the contributions of V. V. Repkin. Secondly, the critical analysis of V. V. Repkin's view of such conception under Subjectivity theory scope. One concludes that the works of V. V. Repkin, attached to Study Activity, deserves to be recognized as an important support in the field of psychology and Marxist didactic of that time with contributions still occurring to these days. It has incurred in philosophical and conceptual mistakes which could be considered expression of a time and of a specific moment in the development of psychological and didactic science in the soviet period. Based on the Subjectivity theory, the main critics to V. V. Repkin's work about Study Activity are: the character, at least apparently determinist of the objective activity (external) in relation to the subjective one (internal); the understanding of Study Activity as internalization process of knowledge, thus negating the generative and creative character of the subject who learns; the predominance of the cognitive character of didactic processes, hence denying the unity of the symbolic and the emotional in the constitution of the subjectivity; the negation of the pupil as subject of the own activity.
\end{abstract}

KEYWORDS: Study Activity; V. V. Repkin; Theory of Subjectivity.

\title{
Introdução
}

A didática Desenvolvimental da Atividade é uma concepção de aprendizagem que surgiu na ex-União Soviética, na segunda metade da 
década de 1950, com base nas teses de Vigotski sobre o papel do processo de obutchénie ${ }^{5}$ no desenvolvimento do psiquismo humano. A mesma tinha como objetivo estabelecer os fundamentos teóricos e metodológicos de uma educação escolar voltada para a formação das crianças, a partir da organização didática dos processos, ora privilegiando um método geral de assimilação cognitiva dos conceitos e das ações mentais (sistema GalperinTalízina), ora os conteúdos enquanto objetos de aprendizagem para a formação do pensamento teórico (sistema Elkonin-Davidov-Repkin), ora os métodos específicos de aprendizagem dos conhecimentos particulares (sistema Zankoviano) (PUENTES, 2017, 2018; PUENTES; LONGAREZI, 2013, 2017a,b, 2018; LONGAREZI; PUENTES, 2017; PUENTES; AMORIM; CARDOSO, 2018; PUENTES; CARDOSO; MARIM; MUSIYCHUK, 2018).

No interior do sistema Elkonin-Davidov-Repkin, especificamente, foram geradas numerosas teorias centrais e auxiliares. A Atividade de Estudo é a teoria central desse sistema ${ }^{6}$ e seus pressupostos foram elaborados no contexto da teoria da atividade de L. S. Vigotski, S. L. Rubinstein e A. N. Leontiev. Esse último autor estabeleceu o conceito de "atividade principal" compreendendo-a como aquela no interior da qual 1) surgem novas formas de atividade, 2) formam-se e reorganizam-se processos psíquicos específicos, 3) e, ao mesmo tempo, pode ser considerada responsável, em maior grau, pelas alterações psicológicas básicas que a personalidade da criança experimenta em cada período do desenvolvimento humano.

Além disso, Leontiev identificou também o tipo particular de "atividade principal” que corresponde a cada um dos períodos do desenvolvimento humano (LEONTIEV, 1945/1959, p.289). De acordo com o autor, enquanto

\footnotetext{
5 "Decidimos utilizar o termo em russo [...] por não existir uma tradução adequada para o português [...] Na cultura russa, a palavra obutchénie expressa a unidade constitutiva da atividade docente que encerra tanto a atividade didática do professor quanto a atividade de autotransformação dos alunos." (LONGAREZI; PUENTES, 2017, apresentação).

${ }^{6}$ Além das teorias psicológica e didática, que foram consideradas o núcleo central do sistema, elaborou-se um sistema de teorias auxiliares: da generalização substantiva (teórica), da modelagem genética, da formação do pensamento teórico e reflexivo, do movimento de ascensão do abstrato ao concreto, do processo de transição de um nível de ensino para o outro, do diagnóstico da atividade de estudo, da colaboração na atividade de estudo e da formação de professores para a atividade de estudo (PUENTES, 2018).
} 
na etapa da idade pré-escolar (que se estende entre os 3 e 6 anos de idade), a atividade principal é a Brincadeira ou o Jogo de Papéis; na etapa da idade escolar inicial (entre 7 e 10 anos de idade), a atividade principal é a Atividade de Estudo. Contudo, nem Leontiev, nem nenhum outro teórico soviético envolvido no estudo da atividade, tais como P. Ya. Galperin, N. F. Talizina, L. I. Bozhovich, N. O. Morozova, L. S. Slavina, B. G. Ananiev, L. V. Zanokov etc., elaborou uma teoria psicológica específica para a Atividade de Estudo. Segundo D. B. Elkonin (1965/1989):

A atividade de estudo como um todo, a sua estrutura objetiva e as leis de seu desenvolvimento têm sido quase totalmente negligenciadas pelos psicólogos na pesquisa. Há uma série de estudos sobre aspectos específicos, embora importantes, da atividade de estudo. Por exemplo, há um estudo dos motivos da atividade de estudo (L.I. Bozhovich; N.O. Morozova; L.S. Slavina, 1951) e sua avaliação (B.G. Ananiev, 1980) e estudos dos problemas da aprendizagem consciente (A.N. Leontiev). Mas, essas pesquisas não exploraram a estrutura da atividade de estudo, o processo de sua formação, nem seu papel de liderança no desenvolvimento psíquico dos alunos menores. (ELKONIN, 1965/1989, p.213).

Onze anos depois de Elkonin, V. V. Repkin (1976c), ainda questionava os modelos teóricos de assimilação que ainda estavam em vigência na época por ignorarem completamente o conceito de atividade objetiva. Além disso, ressaltava a teoria da formação por etapas das ações mentais e conceitos intelectuais de P. Ya. Galperin e N. F. Talízina, para a qual o conceito de atividade era básico e primordial, mas continha duas grandes limitações. Em primeiro lugar, não impulsionava a solução do problema da formação da Atividade de Estudo, porque tinha como objeto a gênese dos conceitos que se constituem na ação e não a formação das próprias ações. Em segundo lugar, esclarecia as condições de assimilação pelo sujeito de um sistema de 
operações, adequado para a tarefa dada, mas não as condições e mecanismos de surgimento das próprias tarefas. A esse respeito Repkin (1976c) afirmou:

O objeto da teoria [da formação por etapas dos conceitos e das ações mentais] é a gênese das formas ideais ("intelectuais") de ação, e não a gênese da ação como tal [...] "De acordo com isso, a análise concentrou-se no estudo da execução das ações estabelecidas. No que concerne à geração delas, ou seja, ao processo de criação de objetivos e de motivação da atividade (no caso em questão de estudo), que elas realizam, isto ficou fora da pesquisa direta (LEONTIEV, 1974, p. 135).” (REPKIN, 1976c, p. $32)$.

A ausência de trabalhos que examinassem o processo de formação, na experiência do indivíduo, de novas formas de atividade objetiva, inclusive da Atividade de Estudo, na experiência do indivíduo, obrigou a construção de um modelo teórico de tal processo como um problema especial da ciência psicológica. Com base nisso, numerosos representantes do sistema ElkoninDavidov, tais como D. B. Elkonin, V. V. Repkin, V. V. Davidov, A. M. Márkova, P. S. Zhedek, M. Ya. Levina, L. E. Shagalova, G. A. Zuckerman, K. K. Mikulina, F. G. Bodansky, V. V. Rubtsov, A. Z. Zak, entre outros, assumiram a tarefa de elaborar possíveis soluções que se baseavam em noções sobre a natureza da atividade humana e sua gênese, cuja essência estava contida nas pesquisas de A. N. Leontiev (cf. DAVIDOV, 1977). As investigações tinham como objetivo determinar os mecanismos psicológicos da Atividade de Estudo, bem como seu conteúdo e estrutura.

A magnitude, profundidade e o alcance teórico, experimental e prático, atingido pela Atividade de Estudo, ao longo dos anos, fizeram dela uma das maiores contribuições no campo da didática marxista das últimas décadas. Isso gerou o surgimento no ocidente, inclusive no Brasil, de numerosos admiradores, seguidores e estudiosos. Porém, observa-se também que o apego fervoroso aos clássicos da teoria levou, muitas vezes, a sua adoção 
desacompanhada da crítica e atualização necessária; bem como ao surgimento de posturas mecanicistas, dogmáticas e anti-dialéticas que têm não somente comprometido seu próprio desenvolvimento, mas também a qualidade das pesquisas que a partir de seus fundamentos se realizam.

Na contramão, a Teoria da Subjetividade de Fernando L. González Rey (1997, 2005, 2016) e seus seguidores, aporta, desde o nosso ponto de vista, recursos teóricos, epistemológicos e metodológicos importantes para a construção de uma visão complexa, dialética e dialógica dos processos de ensino-aprendizagem-desenvolvimento. Além disso, permite, em primeiro lugar, a análise crítica das diferentes concepções didáticas, em especial, da Didática Desenvolvimental da Atividade, de seus diferentes sistemas e da teoria da Atividade de Estudo, já que, ao mesmo tempo em que considera suas relevantes contribuições, não ignora suas limitações; em segundo lugar, o avanço na direção da elaboração das bases de uma nova teoria da Atividade de Estudo na perspectiva da subjetividade.

Em tal sentido, o presente artigo tem como objetivos, por um lado, apresentar os aspectos mais relevantes da Didática Desenvolvimental da Atividade, a partir da análise das principais contribuições teóricas e metodológicas de V. V. Repkin, autor praticamente desconhecido no Brasil e considerado o terceiro mais importante representante do sistema ElkoninDavidov-Repkin, à Teoria da Atividade de Estudo; pelo outro, avaliar criticamente as limitações teóricas dessa concepção a luz dos pressupostos da Teoria da Subjetividade.

\section{A teoria da Atividade de Estudo}

As teses iniciais sobre a teoria da Atividade de Estudo foram sendo elaboradas de maneira simultânea, entre o final da década de 1950 e 1970, nos campos da psicologia cultural-histórica, da didática geral e da metodologia da aprendizagem. O objetivo era determinar a estrutura dessa atividade, as leis de sua formação e sua relação no desenvolvimento psíquico 
da criança e ir criando no plano experimental as condições didáticas adequadas para sua formação no espaço da sala de aula das escolas em massa (PUENTES, 2017, 2018).

A maior parte dos trabalhos foi realizada pelas equipes de Moscou e Kharkov sob a supervisão de Elkonin e Repkin para o caso específico da psicologia; e de Repkin e Davidov para os experimentos didáticos realizados nas escolas n 91 (Moscou, Rússia) e n 4 (Kharkov, Ucrânia). Sobre o objeto e o papel da Atividade de Estudo Elkonin (1961a) escreveu:

...a autotransformação da própria criança como produto (é o objeto da atividade de estudo), a partir das transformações que se operam durante a execução no objeto... (p. 240).

A atividade de estudo é fundamental na idade escolar, porque, em primeiro lugar, por intermédio dessa se realizam as relações básicas da criança com a sociedade; em segundo, porque na escola tem lugar a formação tanto das qualidades fundamentais da personalidade da criança de idade escolar, como dos distintos processos psíquicos [...] O estudo das regularidades da formação da atividade de estudo, é o problema central da psicologia das idades, isto é, da psicologia da idade escolar. (ELKONIN, 1961a, p. 240).

Elkonin (1961a), também determinou que a efetivação da Atividade de Estudo dependia da adequada reorganização substancial do processo de ensino; estabeleceu as condições básicas para o processo de sua formação (o conteúdo do material que se assimila, a metodologia concreta de ensino e as formas de organização do trabalho de ensino dos escolares) e identificou os componentes de sua estrutura: a) o ensino e os motivos cognitivos; b) os objetivos - a tarefa - e as operações de estudo; c) a ação de controle; d) a ação de avaliação. Contudo, esse autor não resolveu a questão de como gerar, de maneira mais eficiente, a Atividade de Estudo nas crianças e em qual ordem devem ser transferidos alguns de seus elementos para a autor realização. 
Essa problemática, assim como outras tantas, ficou em aberto durante toda a década de 1960.

\section{A teoria da Atividade de Estudo na perspectiva de V. V. Repkin.}

O filólogo, psicólogo e didata ucraniano V. V. Repkin (PUENTES; AMORIM; CARDOSO, 2017, 2018), deu continuidade as pesquisas de Elkonin relacionadas à Atividade de Estudo. Nesse sentido, realizou importantes experimentos de caráter psicológico e didático, cujas teses fundamentais estão contidas em uma série de artigos teóricos publicados entre 1975-1978, dedicados: ao conceito, estrutura, formação como problema psicológico, bem como as condições didáticas de sua formação nos primeiros anos escolares.

De acordo com Dusavitskii (1999), o grupo de Kharkov, sob a direção de Repkin, desenvolveu uma singular capacidade para estudar, simultaneamente, as bases teóricas da Atividade de Estudo e criar sistemas de formação da concepção teórica na forma de um projeto real. O foco de interesse desse grupo esteve nos problemas estritamente psicológicos do ensino. Enquanto Elkonin e Davidov, com o grupo de Moscou, concentraram seus estudos na elaboração e avaliação experimental das proposições estritamente teóricas de uma concepção psicológica de ensino desenvolvimental; V. V. Repkin, com sua equipe, ocupava-se dos problemas da idealização de um sistema de ensino que incorporasse essa concepção.

Seus trabalhos ressaltam diferentes aspectos importantes da Atividade de Estudo. Em primeiro lugar, as características específicas desse tipo de atividade em relação ao trabalho, ao ensino, a assimilação e a aprendizagem. Em segundo lugar, sua função social que é prover as novas gerações com os conhecimentos científicos que operam como premissas universais no domínio das formas de atividade de trabalho. Em terceiro, a assimilação das formas generalizadas de ações e dos conhecimentos científicos que lhe servem de base como seu conteúdo (REPKIN, 1976a). 
Repkin definiu a própria Atividade de Estudo como a unidade de análise mais simples. Além disso, propôs um novo modelo teórico da estrutura dessa atividade que foi tomado na forma mais desenvolvida e que passa pela redefinição dos elementos que o integram: a) a atualização do interesse cognitivo-teórico presente; b) a definição do motivo-meta de estudo final; c) a definição preliminar do sistema de metas intermediárias e das formas de seu alcance; d) a execução do sistema de ações de estudo próprias, cujo lugar central é ocupado pela transformação específica do objeto e a construção de seu modelo; e) as ações de controle; f) as ações de avaliação (REPKIN, 1976b).

Repkin (1976c), também considerou a Atividade de Estudo como uma forma especial de atividade do indivíduo que surge como resultado das condições e mecanismos de sua "apreensão". Ficou assim colocada a ideia de que a formação desse tipo de atividade é resultado do processo de assimilação das formas de atividade historicamente criadas pela humanidade. Sugeriu um sistema de noções sobre a base das quais se forma a Atividade de Estudo. Descreveu o conteúdo e os resultados de pesquisas de laboratório realizadas sobre a aplicação do modelo teórico concebido para a análise das particularidades da Atividade de Estudo, com base nas etapas antecedentes de sua formação na idade escolar inicial. (REPKIN, 1978).

Em parceria com outros autores, também relatou as condições externas necessárias ao processo de desenvolvimento da Atividade de Estudo e identificou os elos da mesma como um processo de solução de tarefas, os quais são: 1) a proposição da tarefa de estudo, 2) a aplicação de formas ideais de sua solução (modelagem), 3) a realização do controle do andamento da solução, 4) a avaliação objetiva de seus resultados (REPKIN, 1975).

Por fim, reformulou sua concepção a respeito da Atividade de Estudo, seu lugar no contexto da Didática Desenvolvimental, seu conceito e sua estrutura. Centrou sua análise nas necessidades, objetivos e tarefas da 
Atividade de Estudo, com base na discussão das obras dos principais representantes do sistema Elkonin-Davidov (1997/2014).

Diante da relevância dos trabalhos de Repkin relacionados à Atividade de Estudo, numerosos representantes desse sistema didático realizaram novas pesquisas com base nas teses desse autor. Inclusive, V.V. Davidov ressaltou em suas obras o valor teórico e metodológico desses estudos, bem como a sua vigência ainda nas décadas de 1980 e 1990 (cf. DAVIDOV; MÁRKOVA, 1981; DAVIDOV, 1986, 1996, 2000).

\section{A Teoria da Subjetividade}

As bases dessa teoria foram estabelecidas a partir da segunda metade da década de 1990 (GONZÁLEZ REY, 1997). Suas teses se sustentam nas posições filosóficas de C. Marx, Maurice Merleau-Ponty e Edgar Morin, na psicologia cultural-histórica de L. S. Vigotski, S. L. Rubinstein, L. I. Bozhovich, V. E. Chudnovaky, K. A. Abuljanova, B. F. Lomov e B. G. Ananiev, bem como nas concepções psicológicas da personalidade de G. Allport e F. Guattari. A mesma, parte do pressuposto do caráter gerador da psique, com o qual entra em contradição com as concepções psicológicas marxistas que lhe precederam, sobretudo, com a teoria cultural-histórica da atividade, de A. N. Leontiev e seguidores.

Com base no caráter gerador da psique, a teoria da subjetividade reafirma o conceito do papel ativo do sujeito enquanto produtor criativo de sua própria existência (MITJÁNS MARTÍNEZ; GONZÁLEZ REY, 2017). Nessa perspectiva, o sujeito se constitui, enquanto tal, através do modo particular como produz a sua subjetividade a partir das experiências vividas. O sujeito é definido como a pessoa envolvida ativamente na delimitação e desenvolvimento de espaços pessoais dentro das atividades sociais que realiza e a subjetividade como aquelas formas complexas em que o psicológico se organiza e funciona na pessoa, cultural e historicamente constituída e nos espaços sociais das suas práticas e modos de vida. 
Desse modo, a subjetividade remete, em primeiro lugar, às formas de organização e ao desenvolvimento dos processos simbólicos e emocionais, como unidade inseparável, na atividade humana. Em segundo, às ações indiretas e encobertas da influência das experiências vividas pelo sujeito, que se entrelaçam e se expressam em rápidos desdobramentos simbólicos e emocionais, aparecendo estreitamente articulados entre si e gerando cadeias de efeitos que atuam apenas no nível subjetivo. Em terceiro, aos sentidos subjetivos que se constituem a partir da unidade desses processos simbólicos e emocionais, na qual uns emergem perante a presença dos outros, sem ser sua causa (GONZÁLEZ REY, 2013).

Os sentidos subjetivos constituem a organização simbólico-emocional que a experiência vivida adquire e se manifestam nas mais diversas expressões humanas. Os sentidos nunca se revelam em sua integridade em nenhuma dessas expressões quando são tomadas separadas, nem se configuram como resultado de experiências externas que se transformam em internas, mas como uma produção subjetiva que se integra em diversas configurações subjetivas atuais em torno das emoções e processos simbólicos que se expressam no decorrer das ações em diversas áreas de sua condição social atual (GONZÁLEZ REY, 2013). Recentemente o conceito de sentido subjetivo foi definido como:

A relação particular que se produz entre os processos simbólicos e emocionais num espaço de atividade culturalmente delimitado do indivíduo no qual ambos os processos se implicam de forma recíproca sem que um seja a causa do outro (MITJÁNS MARTÍNEZ; GONZÁLEZ REY, 2017, p. 54).

O simbólico faz referência a todos aqueles processos que substituem, transformam e sintetizam sistemas de realidades objetivas em realidades humanas que só são inteligíveis na cultural. Constituem o simbólico as imagens, a fantasia, a imaginação e tudo aquilo que é capaz de gerar esses 
processos singulares que resultam irreconhecíveis na experiência vivida de modo direto. $\mathrm{O}$ sentido subjetivo, portanto, não existe, não está substancializado, não representa um tipo específico de comportamento ou um conteúdo psíquico concreto. O sentido se expressa quando é demandado pelo próprio sujeito na atividade humana que realiza.

As configurações subjetivas, por sua vez, representam as articulações de sentidos subjetivos em que se organizam tanto a subjetividade individual quanto a social. As mesmas se expressam em duas dimensões: configurações subjetivas da personalidade ${ }^{7}$ e configurações subjetivas da ação. As primeiras são organizações dinâmicas de sentidos subjetivos que têm adquirido uma relativa estabilidade no percurso da história de vida do indivíduo e que:

...mesmo que se organizem e se reorganizem de formas diversas perante as situações que o indivíduo vive, ocupam, pela sua força, um lugar importante na organização da subjetividade individual. A estabilidade relativa que referimos à organização das configurações subjetivas da personalidade não ocorre porque elas aparecem através de sentidos subjetivos idênticos nas diferentes áreas da atividade humana, mas porque aparecem por sentidos subjetivos que têm uma elevada convergência. (MITJÁNS MARTÍNEZ; GONZÁLEZ REY, 2017, p. 56).

Já as configurações subjetivas da ação fazem menção à emergência de sentidos subjetivos que se configuram no curso da ação, os quais expressam as configurações subjetivas da personalidade que cobram significação no curso da ação.

É preciso ressaltar a distinção que existe entre as configurações subjetivas da personalidade e as configurações subjetivas da ação. Essa distinção permite compreender que entre personalidade e ação não há relação linear de causalidade, porque uma não determina à outra a priori.

\footnotetext{
${ }^{7}$ A personalidade é entendida como uma configuração de configurações subjetivas.
} 
A subjetividade, vista no contexto das práticas pedagógicas escolares, remete a ideia de que a organização adequada dos processos de ensinoaprendizagem não leva necessariamente ao desenvolvimento desejado dos estudantes. Há uma relação de reciprocidade entre desenvolvimento da personalidade dos sujeitos que participam do processo e as práticas didáticas que realizam, mas a mesma não é determinista. De acordo com González Rey (2013):

Pelo caráter gerador da psique, eventos aparentemente intranscendentes em sua significação objetiva são 'responsáveis' por uma produção subjetiva que tem muito mais a ver com as configurações subjetivas do sujeito, do que com o evento em questão. (GONZÁLEZ REY, 2013, p.268).

Esse é o motivo pelo qual é possível afirmar que os sentidos subjetivos emergem além da intencionalidade e da consciência do indivíduo. Com outras palavras, eles não estão subordinados à racionalidade dos atores envolvidos, sejam eles sociais ou individuais.

$\mathrm{Na}$ perspectiva da subjetividade, a aprendizagem é definida como uma real personalização do aprendido que permite ao aluno sua utilização em situações novas e sua integração com outros conhecimentos e experiências que ampliem suas representações ou que gerem ideias e ações que vão além do que foi apresentado (MITJÁNS MARTÍNEZ; GONZÁLEZ REY, 2017, p. 60). O desenvolvimento, por sua vez, é entendido como o processo de formação de novos recursos subjetivos que permitem ao indivíduo mudanças qualitativas em áreas diversas da vida e que geram um envolvimento pessoal cada vez mais profundo na área em que a configuração subjetiva do desenvolvimento se organiza. De acordo com os autores:

...recursos subjetivos são todas as produções, funções e operações de indivíduos e grupos portadores de sentidos subjetivos, as que aparecem subjetivamente configuradas. $\mathrm{Na}$ realidade, 
consideramos que as funções psicológicas passam a ser um recurso subjetivo quando emergem subjetivamente configuradas. Em Vygotsky há uma ideia, que como muitas outras tantas ficou isolada, quando em sua obra Pensamento e Fala, afirmou que o pensamento expressava a completa vitalidade do indivíduo que pensa. É essa vitalidade que aparece quando o pensar se configura subjetivamente. Por exemplo, a capacidade reflexiva é um recurso subjetivo, pois implica a imaginação e a emergência de uma emocionabilidade associada com múltiplos sentidos subjetivos que não se esgotam pelas emoções geradas pelo foco da reflexão.

(GONZÁLEZ REY; MITJÁNS MARTÍNEZ, 2017).

A teoria da subjetividade sustenta a tese de que, se bem os processos de ensino-aprendizagem podem gerar sentidos subjetivos imprevisíveis e muitas vezes contrários aos desejados, o papel do ensino e a aprendizagem é fundamental no desenvolvimento humano. Só a obutchénie é capaz de criar as condições adequadas e potencializar o desenvolvimento de recursos subjetivos.

A aprendizagem só é adequada quando a configuração subjetiva que se forma torna-se uma configuração subjetiva do desenvolvimento que leva ao progresso de novos recursos subjetivos do sujeito que vão além da disciplina que se aprende. (MITJÁNS MARTÍNEZ; GONZÁLEZ REY, 2017, p. 73).

\section{Abordagem crítica da Atividade de Estudo na obra de V. V. Repkin a luz da Teoria da Subjetividade}

Na década de 1950, depois da morte de Stalin, a Teoria da Atividade passou a preencher o vácuo deixado pelos processos neurofisiológicos que tinham como pressupostos teóricos as teses de I. Pavlov (1849-1936). Na perspectiva de Leontiev, a atividade era compreendida como externa, prática, concreta e objetiva, que se transformava em interna e subjetiva a 
partir da assimilação ou interiorização pelo sujeito dos objetos (conteúdos objetivos) (GONZÁLEZ REY, 2016).

Essa mesma postura foi assumida pelos representantes da teoria da Atividade de Estudo, inclusive por V. V. Repkin (1978), que, a respeito dos pontos básicos que determinam o processo de formação dessa atividade, afirmou:

...eles determinam os principais momentos da transformação da estrutura objetiva da atividade de estudo, realizada inicialmente pelos mecanismos interpsíquicos da interação do professor com os alunos [...] sustentada em mecanismos intrapsíquicos que por si só se formam no processo de ensino-aprendizagem... (REPKIN, 1978, p.10).

O processo de transformação da atividade objetiva em subjetiva, pela via do trânsito do interpsicológico para intrapsicológico, tal e como formulado por L. S. Vigotski em sua teoria da assimilação, criou uma separação entre as operações externas com objetos e a consciência, sobre cuja base essa última passou a ser resultado da internalização das operações externas.

Por outro lado, os termos assimilação, aquisição e apreensão são empregados de maneira reiterada nos trabalhos de Repkin e eles sempre expressam o mesmo sentido: a formação da Atividade de Estudo é resultado de um longo processo de interiorização das formas de atividade historicamente criadas pela humanidade. A esse respeito Repkin (1976b) diz:

O próximo componente da atividade de estudo é o sistema de ações que asseguram o alcance da meta prevista. Isto é, a assimilação de um determinado conceito (ou de uma forma de ação)... 
A meta de estudo no caso em questão consiste em assimilar os modos de obtenção dos conceitos, 'das condições e leis da origem dos conceitos' (DAVIDOV, 1972, p. 375). (REPKIN, 1976b, p.3).

Com isso, é evidente que Repkin, desconsidera a impossibilidade de que a subjetividade seja assimilada. A subjetividade não é algo externo ao sujeito que aparece dentro, a partir de um conjunto de etapas e de condições de internalização que permitem transformar a subjetividade social em individual, na medida em que a estrutura da atividade se modifica. Da mesma forma, ignorou a relação intrínseca e recíproca que existe entre as formas de atividade historicamente criadas pela humanidade, o sujeito e a subjetividade, entre as quais apenas considerou a existência de determinadas relações, assumindo com isso uma posição supostamente mecanicista que lhe impediam ver esses fenômenos como componentes integrados. A esse respeito González Rey (2005) afirmou:

Temos de substituir a visão mecanicista de ver a cultura, sujeito e subjetividade como fenômenos diferentes que se relacionam para passar a vê-los como fenômenos que, sem serem idênticos, se integram como momentos qualitativos da ecologia humana em uma relação de recursividade. (GONZÁLEZ REY, 2005, p.78).

A compreensão da obutchénie, como um processo de interiorização ou assimilação da experiência externa, por intermédio da qual o sujeito se apropria da subjetividade social e a torna sua na forma de subjetividade individual, levou Repkin (1976b,c) a uma ideia da consciência enquanto reflexo subjetivo da realidade objetiva, negando qualquer possibilidade de aceitação do caráter gerador do sujeito. Visto dessa maneira, a Atividade de Estudo dos alunos na escola consistia em reproduzir os conhecimentos científicos e os modos de atuação historicamente criados e que aparecem cristalizados nos conteúdos escolares. A esse respeito Repkin (1976b) afirmou: 
Como toda teoria, esta [atividade de estudo] deve refletir o seu objeto "desde suas ligações internas e leis de movimento" (Kopnin, 1973, p. 133). A construção desta teoria começa pela análise das formas desenvolvidas do objeto, tendo por fim a definição em primeiro lugar de sua essência, definindo na forma mais geral - e, portanto abstrata - a construção do objeto, sua estrutura. (REPKIN, 1976b). (destaque nosso)

A respeito dessa postura do materialismo mecanicista na psicologia marxista do período soviético, González Rey (2005) afirmou:

Em geral, a psicologia soviética tratou de resolver a questão da formação social do psíquico mediante dois processos fundamentais: o reflexo e a interiorização. Em ambas as formas, a atribuição do caráter primário ao objeto era fundamental. (GONZÁLEZ REY, 2005, p.80).

Sendo assim, a ideia de definir a obutchénie como processo de produção criativa de sentidos subjetivos na Atividade de Estudo, tal e como é colocada por Mitjáns Martínez e González Rey (2017), não está presente na obra de Repkin. Pelo contrário, a Atividade de Estudo, longe de ser produto da criatividade, é um ato de internalização do indivíduo que aprende. A esse respeito Repkin (1976c) afirmou:

A atividade de estudo não é um produto da criatividade do indivíduo, não é inventada por ele. Ele pode apenas assimilar ("apreender") aquelas formas de atividade de estudo historicamente criadas, as quais ele encontra prontas e que lhe são dadas sob a forma de atividade de outras pessoas... (REPKIN, 1976c, p.32). (Destaque nosso). 
Nesse sentido, o papel da didática tinha ficado reduzido a questão das condições e mecanismos de "apreensão" pelo indivíduo daquelas formas de Atividade de Estudo historicamente criadas pela humanidade. Com isso, deixou-se fora do processo o próprio indivíduo enquanto sujeito de sua atividade. Repkin (1997/2014) chegou afirmar: “...não é o ser humano que domina a atividade, mas a atividade que domina o ser humano." (p.89). A busca pela objetividade levou Repkin, da mesma maneira que tinha levado antes e na mesma época a outros representantes soviéticos, a ignorar o lugar do sujeito que aparece como um momento da atividade. De acordo com González Rey (2016):

A atividade foi tomada como um sistema em si mesmo, com sua estrutura e suas leis próprias: a atividade funcionava independentemente de seu sujeito, como funcionava a mente como sistema de processamento da informação na definição dos pioneiros da "revolução cognitiva norte-americana". (GONZÁLEZ REY, 2016, p.46).

Ao mesmo tempo, o indivíduo foi colocado como algo inerente para a espécie, ligado a um princípio universal, racional e abstrato, negando com isso a condição singular do sujeito, seu caráter concreto, já presente em Vigotski e Rubinstein (GONZÁLEZ REY, 2005). Por outra parte, observa-se na obra de Repkin o predomínio de uma postura determinista e causal dos fenômenos externos, aos quais atribuía caráter primário, em relação aos fenômenos internos, de caráter secundário, sustentou-se na ideia da natureza idêntica da estrutura da atividade interna em relação com a externa. Para Repkin, a Atividade de Estudo era um produto acidental ou acessório da atividade externa, sobre a qual não tinha efeitos próprios. Sendo assim, as fragilidades que González Rey identificou em relação a Teoria da Atividade podem ser atribuídas a teoria da Atividade de Estudo desenvolvida por Repkin. A esse respeito, González Rey (2016) afirmou: "Leontiev, em seu intuito de superar qualquer reminiscência de idealismo 
em seus posicionamentos, identificou a atividade interna e a externa como tendo uma mesma estrutura, como resultado do qual a atividade interna foi transformada em um epifenômeno da externa." (GONZÁLEZ REY, 2016, p. 47).

Está ausente também nos trabalhos de Repkin uma noção de subjetividade que nos remete às formas de organização e ao desenvolvimento dos processos simbólicos e emocionais como unidade inseparável na atividade humana do indivíduo. Pelo contrário, observa-se em sua teoria da Atividade de Estudo, o caráter eminentemente cognitivista dos processos didáticos, presente no seu objeto (a formação do pensamento teórico) e nos componentes que integram seu conteúdo: a assimilação das formas generalizadas das ações e dos conhecimentos científicos que lhe servem de base para a formação do pensamento teórico.

A ideia que prevalece aqui é a de que a formação das funções psicológicas cognitivas, o pensamento teórico nessa fase do ensino fundamental (primeiras séries), determina nesse período do desenvolvimento humano as demais funções, sobretudo, aquelas de caráter emocional, tais como, os afetos, sentimentos e emoções. Assim, do mesmo modo que a atividade psicológica é vista como um epifenômeno da atividade objetal externa; as emoções e os afetos são considerados um epifenômeno do pensamento teórico.

Outro componente importante da estrutura da Atividade de Estudo, de acordo com Repkin (2014), era a necessidade. Segundo o autor, a preservação da continuidade de um período do desenvolvimento para o outro na vida do sujeito, só estava garantida quando a Atividade de Estudo passava a estar associada à ação efetiva do sujeito. Ao mesmo tempo, essa ação precisava ser uma resposta a algum tipo específico de necessidade. Repkin (2014) escreveu: "Se não há necessidade, logo não há atividade. Diferentes tipos de atividade humana assumem formas distintas a medida que surgem novas necessidades. Cada tipo de atividade é, antes de tudo, uma resposta a algum tipo de necessidade..." (REPKIN, 1997/2014, p.91). 
Contudo, Repkin teve dificuldades para explicar como se formam as necessidades psicológicas, especificamente humanas. Segundo ele, as mesmas só surgem a partir do encontro das necessidades iniciais, consideradas inerentes ao organismo humano, com os objetos que as satisfazem (o conteúdo escolar), agindo como estímulo direto, isto é, como motivo. A esse respeito diz: "A necessidade em si não é suficiente para produzir atividade. O encontro com o objeto deve acontecer. Esse objeto, que é capaz de satisfazer a necessidade, é o estímulo direto. Na psicologia, isso é chamado de motivo." (REPKIN, 1997/2014, p.92).

Nessa perspectiva, a necessidade biológica se torna motivo, como resultado de seu encontro com o objeto externo, o que leva ao surgimento das necessidades psicológicas. Dessa maneira, aparentemente mecanicista, o objeto e a necessidade aparecem a priori da própria atividade, como realidades objetivas dadas; a atividade assume a função de simples mediação entre a necessidade e seu objeto; o motivo é entendido como a peça da atividade externa com objetos. A respeito, González Rey (2016) afirmou, “...a necessidade se torna motivo como resultado de seu encontro com um objeto externo, no que parece uma solução mágica em que o "toque" do objeto na necessidade a transforma de biológica em psicológica..." (GONZÁLEZ REY, 2016, p.48).

Nessa concepção de motivo de Repkin, os sentimentos, lembranças, reflexões e decisões da pessoa, de acordo com o próprio González Rey (2016), não têm nada a ver com a motivação de seu comportamento. $\mathrm{O}$ aluno, como sujeito da Atividade de Estudo, é substituído pelo objeto (o conhecimento científico). Na opinião de Repkin, o motivo-meta da atividade se forma no sujeito, como resultado de um processo lento e complexo de "redefinição" da meta externa. O que determina que o conhecimento científico, possa tornarse motivo-meta é externo ao sujeito, pois depende, por um lado, da existência dos conceitos científicos como uma forma especial de generalização dos modos de atividade cognitiva e prática; pelo outro, de que 
esse próprio conhecimento esteja ligado pelo conteúdo com as necessidades presentes no estudante.

\section{Considerações finais}

A Atividade de Estudo é a principal teoria desenvolvida no interior do sistema Elkonin-Davidov. Nenhum outro sistema didático elaborou uma proposta teórica e metodológica dessa magnitude. Sua definição, conteúdo e estrutura, bem como as pesquisas experimentais realizadas a esse respeito, revolucionaram a Didática Desenvolvimental na ex-União Soviética, sobretudo, entre as décadas de 1960 e 1990.

V. V. Repkin, junto com D. B. Elkonin e V. V. Davidov foi um dos principais representantes dessa teoria. Seus aportes fundamentais estiveram tanto na elaboração de uma nova estrutura da mesma, na definição do papel dos motivos, objetivos, interesses cognitivos e necessidades no processo de sua formação quanto na criação das condições didáticas objetivas indispensáveis para isso.

Contudo, a obra do Repkin ficou presa as próprias limitações de sua época: ao caráter determinista da atividade objetiva (externa) em relação a subjetiva (interna); à compreensão da Atividade de Estudo enquanto processo de interiorização dos conhecimentos, em lugar de produção de sentidos subjetivos; ao predomínio do caráter cognitivista dos processos didáticos, com o que se nega a unidade do simbólico e emocional na constituição da subjetividade; à negação do aluno enquanto sujeito de sua própria atividade.

\section{Referências}

ELKONIN, D. B. Психологические вопросы формирования учебной деятельности в младшем школьном возрасте (Problemas psicológicos de formação da atividade de estudos nos escolares de menor idade). In: KOSTIUK, G.; CHAMATA, P. Вопросы психологии обучения и воспитания (Questões de Psicologia do Ensino e da educação). Ucrânia: Kiev, 1961a, p.142-143. 
ELKONIN, D. B. Desarrollo psíquico de los escolares. In: SMIRNOV, A.A.; LEONTIEV, A.N.; RUBINSTEIN, S. L.; TIEPLOV, B. N. (Orgs.). Psicologí $m$ mk9. Habana: Imprenta Nacional de Cuba, 1961b, p.523-559.

ELKONIN, D. B. O структуре учебной деятельности (Estrutura da atividade de estudo). In: ELKONIN, D. В. Избранные психологические труды (obras psicológicas selecionadas). М.: Педагогика, 1965/1989. 560 c.

GONZÁLEZ REY, F. L.; MITJÁNS MARTÍNEZ, A. Recurso subjetivo. E-mail. 06/07/2017.

GONZÁLEZ REY, Fernando L. Marxismo, subjetividad y psicología culturalhistórica: avanzando sobre un legado inconcluso. Teoría y Crítica de la Psicología, n. 7 (2016), p.40-55. Disponível em http://www.teocripsi.com/ojs, acesso em 11 de maio de 2017.

GONZÁLEZ REY, Fernando L. $O$ pensamento de Vigotsky. Contradições, desdobramentos e desenvolvimento. São Paulo: Hucitec, 2013.

GONZÁLEZ REY, Fernando L. Sujeito e subjetividade. São Paulo: Thomson, 2005.

GONZÁLEZ REY, Fernando L. Epistemología cualitativa y subjetividad. São Paulo: Educ, 1997.

LEONTIEV, A. N. К теории развития психики ребенка (Teoria psicológica do desenvolvimento infantil). «Советская педагогика», 1945, № 4. In: LEONTIEV, A. N. Проблема развития психики (Problema do desenvolvimento psíquico). Moscou: Academia de Ciências Pedagógicas da URSS, 1959, p.286-302.

LONGAREZI, Andréa Maturano; PUENTES, Roberto Valdés. Fundamentos psicológico-didáticos para um ensino na perspectiva histórico-cultural: a unidade dialética obutchénie-desenvolvimento. In: LONGAREZI, Andréa Maturano; PUENTES, Roberto Valdés (Orgs.). Fundamentos psicológicos e didáticos do ensino desenvolvimental. Uberlândia: Edufu, 2017, p.7-16.

MATBEEBA, H. E.; REPKIN, V. V.; CKOTAPEHKO, Р. В. Психологические Предпосьілки Самостоятельньіх фрорм Учебной деятельности (Condições de domínio de formas independentes da atividade de estudo na escola). Вестник, вып. 8, 1975, № 122. C. 42-50.

MITJÁNS MARTÍNEZ, Albertina; GONZÁLEZ REY, Fernando L. Psicologia, educação e aprendizagem escolar. São Paulo: Cortez, 2017.

PUENTES, Roberto Valdés; PUENTES, Roberto Valdés; AMORIM, Paula Alves Prudente; CARDOSO, Cecília Garcia Coelho. Didática desenvolvimental da atividade: contribuições de V. V. Repkin ao sistema Elkonin-Davidov. Ensino em Re-vista, Uberlândia, v.24, n.1, p.267-286, p. 2017. Disponível em http://www.seer.ufu.br/index.php/emrevista/article/view/37687, acesso em 17 de maio de 2017. 
PUENTES, Roberto Valdés. Didática desenvolvimental da atividade: o sistema Elkonin-Davidov (1958-2015). Ubutchénie: R. de Didat. e Psic. Pedag. Uberlândia, MG, v.1, n.1, p.20-58, jan./jun. 2017. Disponível em http://www.seer.ufu.br/index.php/Obutchenie/article/view/38113, acesso em 17 de maio de 2017.

PUENTES, Roberto Valdés; LONGAREZI, Andréa Maturano. Escola e didática desenvolvimental: seu campo conceitual na tradição da teoria histórico-cultural. Educação em Revista (UFMG. Impresso), v. 29, p. 247-271, 2013.

PUENTES, R. V.; LONGAREZI, A. M. A didática desenvolvimental: seu campo conceitual na tradição da psicologia histórico-cultural da atividade. In: LONGAREZI, A. M.; PUENTES, R. V. (Org.). Fundamentos psicológicos e didáticos do ensino desenvolvimental. 1ed. Uberlândia: Edufu, 2017a, v. 5, p. 187-224.

PUENTES, R. V.; LONGAREZI, A. M. Didática desenvolvimental: sessenta anos de tradição teórica, epistemológica e metodológica. Revista Obutchénie, Uberlândia, v. 1, n. 1, Jan./abr., p. 9-19, 2017 b.

PUENTES, Roberto Valdés. Sistema Elkonin-Davidov-Repkin: etapas no desenvolvimento da teoria da atividade de estudo (1959-2018). Anais... 17 ${ }^{a}$ Jornada do Núcleo de Ensino e $4^{\circ}$ Congresso Internacional sobre a Teoria Histórico-Cultural - Significado e sentido na educação para a humanização, Faculdade de Filosofia e Ciências da UNESP, Câmpus de Marília, 20 de setembro de 2018. Disponível em http://www.inscricoes.fmb.unesp.br/publicacao.asp?codTrabalho=MjcyNDI=

PUENTES, R. V.; AMORIM, P. A. P.; CARDOSO, C. G. C. Дидактика развития деятельности. Fundamental and applied researches in practice of leading scientific schools, v. 27, p. 188-195, 2018.

PUENTES, R. V.; LONGAREZI, A. M. The theory of cognitive abilities in preschool children in works of L. Venguer. Humanitarian and pedagogical Research, v. 2, p. 50-53, 2018.

PUENTES, R. V.; CARDOSO, C. G. C.; AMORIM, P. A. P.; MUSIYCHUK, M. V. Elkonin-Davidov: system: historical aspects (1958-2015). Humanitarian and pedagogical Research, v. 2, p. 6-13, 2018.

REPKIN, V. V. O Формирование Учебной Деятельности В. МладШем Школьном Возрасте (A formação da atividade de estudo na idade escolar primária). Вестник, вып. 11, 1978, № 171. С. 40-49.

REPKIN, V. V. O Понятии Учебной Деятельности (O conceito de atividade de estudo). Вестник, вып. 9, 1976а, № 132. С. 3-10.

REPKIN, V. V. Развивающее обучение и учебная деятельность (Ensino desenvolvimental e atividade de estudo). (Publicado inicialmente na cidade de Riga, 1997). Ensino em Re-vista, Uberlândia, v. 21, n. 1, p. 85-99, 2014. Disponível 
em http://www.seer.ufu.br/index.php/emrevista/article/view/25054/13891, acesso em 17 de maio de 2017.

REPKIN, V. V. Строение Учебной Деятельности (Estrutura da atividade de estudo). Вестник, вып. 9, 1976b, № 132. С. 10-16.

REPKIN, V. V. Формирование Учебной Деятельности Как Психологическая Проблема (A formação da atividade de estudo como um problema psicológico). Вестник, вып. 10, 1976с, № 155. С. 32-38.

DUSAVINSKII, A. K. Доклад на шестой научно-практической конференции Международной Ассоциации. Развивающее обучение. - М., 1999.

DAVIDOV, V.V. (Org.). Психологические проблемы учебной деятельности школьника. Mockba: Sovetskai Russia, Сб, 1977.

DAVIDOV, V.V. ИЗ ИСТОРИИ РАЗВИВАЮЩЕГО ОБУЧЕНИЯ ИЗ ИСТОРИИ СТАНОВЛЕНИЯ СИСТЕМЫ . РАЗВИВАЮЩЕГО ОБУЧЕНИЯ. ВестнИК № 1/ 1996, Disponível em: http://www.experiment.lv/rus/biblio/vestnik_1/v1_davidov_iz_istorii.htm

DAVIDOV, V.V. Теория развивающего обучения. M.: Иhtop, 1996, г. , 544 стр.

DAVIDOV, V. V. Концепция гуманизации россиисккого начального образования (необходимость и возможность создания целостной системы развивающего начального образования). Психологическая наука и образование. п. 2, р. 5-11, 2000.

DAVIDOV, V. V. O понятии развивающего обучения. Публикация в журнале "Педагогика", № 1, 1995 г. Disponível em http://elib.gnpbu.ru/text/davydov_oponyatii-razvivayuschego-obucheniya_1995/fs, 1/

Recebido em março de 2018.

Aprovado em agosto de 2018. 